\title{
The Effects of Natural Chinese Medicine Aconite Root, Dried Ginger Rhizome, and Coptis on Rectal and Skin Temperatures at Acupuncture Points
}

\author{
Jia-Min Yang, ${ }_{1}^{1}$ Gang Li, ${ }^{2}$ Min Wang, ${ }^{1}$ Yi-Xi Jin,, Feng-Jie Zheng, ${ }^{1}$ Yan Sun, \\ Yu-Shan Gao, ${ }^{1}$ Shu-Jing Zhang, ${ }^{1}$ Peng-Fei Kang, ${ }^{1}$ Lin Chen, ${ }^{1}$ Meng-Yao Wu, ${ }^{1}$ \\ Sheng-Yong $\mathrm{Xu}^{2}$, and Yu-Hang $\mathrm{Li}^{1}$ \\ ${ }^{1}$ School of Basic Medical Science, Beijing University of Chinese Medicine, No. 11 Beisanhuan Donglu, Chaoyang District, \\ Beijing 100029, China \\ ${ }^{2}$ Key Laboratory for the Physics \& Chemistry of Nanodevices, Department of Electronics, Peking University, Beijing 100871, China \\ Correspondence should be addressed to Sheng-Yong Xu; xusy@pku.edu.cn and Yu-Hang Li; liyuhang@bucm.edu.cn
}

Received 16 May 2017; Revised 31 August 2017; Accepted 22 October 2017; Published 12 November 2017

Academic Editor: Raffaele Capasso

Copyright (C) 2017 Jia-Min Yang et al. This is an open access article distributed under the Creative Commons Attribution License, which permits unrestricted use, distribution, and reproduction in any medium, provided the original work is properly cited.

\begin{abstract}
The 4 properties of Chinese materia medica refer to cold, hot, warm, and cool. In the present study, the effects of the Coptis, the prepared aconite root, and dried ginger rhizome were compared with regard to the rectal and skin temperature changes of the related body surface acupuncture points (Dazhui, Zhiyang, Mingmen, Zhongwan, and Shenque). The investigation aimed to explore the thermal sensitive points, which can reflect the cold and hot properties of the Chinese herbs. This study showed that the prepared aconite root and dried ginger rhizome exhibited a warming effect on the body temperature, whereas the warming sensitive points were Zhongwan, Shenque, Dazhui, and Zhiyang. Coptis exhibited both a warming and a cooling effect on the body temperature, and the cooling sensitive point was Dazhui. The concomitant effect of these three Chinese herbs on the regulation of the body temperature was reflected by Dazhui. However, there are still some limitations and one-sidedness. For instance, the cold and hot property of some herbs cannot be fully reflected through relevant acupoints on the conception and governor vessels. More detecting sites such as ears and internal organs will be selected for further exploration of Chinese herbs' cold and hot property.
\end{abstract}

\section{Introduction}

Traditional Chinese medicine (TCM) has been used for several thousands of years with documented clinical experience. Due to widespread worldwide use of TCM, certain types of treatment such as Chinese materia medica, acupuncture, moxibustion, massage, and cupping are currently evaluated in the healthcare system as alternative forms of treatment compared with standard medical care. Chinese materia medica is based on the theory of using Chinese medicinal herbs for the therapeutic applications against several forms of disease. Chinese material medica can be classified into 4 categories and 5 types of taste, meridian tropism, ascending and descending, floating and sinking, and poisonous and nonpoisonous properties. The 4 categories of Chinese materia medica refer to cold, hot, warm, and cool properties and can be summarized as cold and hot natural herbal categories. A total of 4 herbal categories are classified according to the reaction of the body following the application of medicinal herbal treatment. The process of treating diseases in TCM is defined as pattern differentiation and treatment (bian zheng lun zhi). The main classification of the syndromes (zheng) is divided into cold and hot syndromes. The drugs that are defined as cold and cool property act by purging heat and lessening the virulence of any pathogenic organism. Thus, they are suitable for diseases of the hot syndromes. Warm and hot drugs dispel cold and invigorate yang, which are mainly indicated for cold syndrome-associated diseases [1].

It has been previously suggested that cold syndrome should be treated by warm and hot medicinal drugs, whereas 
heat syndromes by cold and cool medicinal drugs. On the basis of this theory, the earliest Pharmaceutical monograph, Shen Nong's Materia Medica, formally presented the 4 properties as cold, hot, warm, and cool that referred to the use of Chinese herbs. The 4 properties of the Chinese herbs have been applied in clinical practice for approximately 2,000 years. The application of cold and hot medicinal drugs is contradicted with the nature of the syndrome. According to the description in the Chinese Pharmacopoeia, prepared aconite root (Radix Aconiti Lateralis Praeparata) and dried ginger rhizome (Rhizoma Zingiberis) belong to the Chinese materia medica with hot properties and are commonly used to treat cold syndromes. In contrast to these herbs, Coptis (Rhizoma Coptidis) and common anemarrhena rhizome (Rhizoma Anemarrhenae) belong to the Chinese materia medica with cold properties and are commonly used to treat hot syndromes. Tao Hongjing has suggested during the Liang dynasty that the cold and hot properties of the herbs must be clarified, while the flavor of the herbs can be neglected, which emphasized the importance of cold and hot properties on the application of the clinical medication. Therefore, it is important to explore and clarify the cold and/or hot properties of the Chinese materia medica in order to ensure the clinical safety and efficacy of the herbal medicines.

A total of 4 properties have emerged by the prolonged use of TCM in the daily life and long-term clinical practice. The 4 properties of the herbs were summarized according to different reactions to the human body following medication and/or food administration and according to the different therapeutic effects to the diseases. The cold and hot properties of the Chinese herbs are associated with the range of clinical dosage and the nature of each clinical syndrome. The theory that proposes the treatment of the cold syndrome with hotnatured medicine and the treatment of the hot syndrome with cold-natured medicine indicated that the cold and/or hot properties of the medicine were closely related to the cold and/or hot syndromes of the diseases. In the clinic, Chinese herbs that can be used to reduce and/or eliminate hot syndromes are referred to as cold and/or cool-natured herbs, while those that can be used to reduce and/or eliminate cold syndromes are known as hot and/or warm-natured herbs. It has been suggested that "exuberance of yang can induce hot properties, while exuberance of yin can induce cold properties." The hot syndrome refers to a pathogenic phenomenon of yang exuberance, while the cold syndrome refers to a pathogenic phenomenon of yin exuberance. According to the modern medical practice, the hot syndromes are related to functional hyperactivity, while the cold syndromes are related to functional hypoactivity. Therefore, medicinal drugs that induce cold properties can reduce the pathological hyperactivity, whereas medicinal drugs that induce hot properties can reduce the pathological hypoactivity. The cold and hot properties induced by the clinical application of the Chinese herbs, namely, the treatment of the hot syndrome with hot medicine and the treatment of the cold syndrome with cold medicine, should be taken into consideration in order to avoid the incidence of adverse effects. The medical practitioner Wang Shuhe in the Jin dynasty suggested that patients with yang exuberance syndrome may exhibit adverse effects following administration of Guizhi decoction (a decoction that is used for cold syndrome in Treatise on Cold Damage (Shang han lun)), while patients with yin exuberance may not survive following administration of Chengqi decoction (a decoction that is used for the hot syndrome in Treatise on Cold Damage (Shang han lun)) [2]. The medical practitioner $\mathrm{Xu}$ Dachun in the Qing dynasty suggested that there were differences between prepared aconite root and dried ginger rhizome when used for the same medicinal application with hot properties, while for the same medicinal application of the medicine with cold properties certain differences between the gypsum (Gypsum Fibrosum) and Scutellaria root (Radix Scutellariae) were observed. However the degree of hot and cold properties induced by Chinese herbs was unclear due to the lack of quantitative research methods used for the detection of these properties.

In TCM, the meridian and collaterals exhibit connective and communicative functions between the internal organs and the body surface. The energy of the internal organs can be transmitted to the body surface and/or limbs by the meridian and collaterals. The meridian and collaterals are considered essential for the circulation of the qi and blood, while the acupuncture points are special points used on the surface of the body where the vital energy of the viscera is infused. The functional status of the viscera can be reflected by the corresponding acupuncture points and/or meridians on the surface of the body [3]. Qijing Bamai Kao has previously stated that the conception vessel is considered to be the sum of yin meridians, which circulate along the median line of the abdomen and have control functions of the body yin meridians. The governor vessel is considered as a pool of yang meridians, which circulate along the posterior median line and regulate the functions of the yang meridians of the body. The acupuncture points Dazhui (GV14), Zhiyang (GV9), Mingmen (GV4), Zhongwan (CV12), and Shenque (CV8) exhibit an association with the qi and the blood components as demonstrated by the therapeutic indications of the meridians, which do not only reflect the state of qi and blood of the body, but also the state of the internal organs. Therefore, in the present study, the hypothesis of specific points in the body that can reflect the cold and/or hot property of Chinese herbs was proposed. The acupuncture points on the conception and governor vessels were selected to explore the biological response that is associated with the cold and hot properties of the Chinese herbs.

Frigid extremities decoction (Si ni tang), which is composed of prepared aconite root, dried ginger rhizome, and liquorice root (Radix et Rhizoma Glycyrrhizae) can be used clinically to recuperate depleted yang and rescue the patient from collapse. The compatibilities of the flavor of the herbs (i.e., dried ginger rhizome, Coptis, Scutellaria root and ginseng (Radix et Rhizoma Ginseng), Pinellia tuber (Rhizoma Pinelliae), liquorice root, and Chinese date (Fructus Jujubae)) with the hot and/or cold properties can be facilitated by the Pinellia Heart-Draining Decoction (ban xia xie xin tang). Pinellia tuber and dried ginger rhizome are pungent in flavor and possess hot properties, while Scutellaria root and Coptis are bitter in flavor and possess cold properties. The compatibility of these 4 herbs can treat epigastric stuffiness 
and obstruction due to accumulation of cold and hot properties [4]. The dosage and proportion of the medicinal drugs with cold and hot properties can be adjusted by sufficient knowledge of the applications of Chinese herbs by the medical practitioner according to the patient's needs. The precise treatment of each disease requires understanding of the cold and hot properties of the prescription.

Previous studies have attempted to define the degree of cold or hot properties of drugs with regard to the application of Chinese materia medica in TCM clinical treatment [5-8]. A variety of modern scientific technologies have been used to investigate the biomedical effects of the 4 properties, such as animal thermotropism behavior $[9,10]$, infrared thermal imaging [11], microcalorimetry [12], cytological evaluation $[13,14]$, biological photon analysis technology evaluation method $[15,16]$, energy metabolic evaluation method [17, $18]$, and cold and hot associated protein pathways [19, 20]. However, the quantitative methods used for the evaluation of cold and hot properties of the Chinese materia medica are incomplete and require further investigation.

The 4 properties depend on the reaction of the body following drug administration. The direct cold and/or hot conditions are directly observed by thermoregulation, according to the risen or dropped body temperature. Thermoregulation is considered one of the most important and objective indices used for body temperature changes. We hypothesized that a different thermoregulation response could be expected in animals following administration of Chinese herbs with cold and/or hot properties. Previous studies used infrared thermal camera methodologies in order to detect the body infrared images following dried ginger rhizome (hot-natured herb) and Scutellaria root (cold-natured herb) administration and attempted to evaluate the induction of cold and/or hot properties of the Chinese herbs [11]. Yuan et al. [21] established rat models of cold and hot syndromes by separate administration of Chinese herbs with cold and hot properties. The differences between the herbs with cold and hot properties were evaluated by the skin temperature of the nose, eyes, ears, and tails of the rats that were detected by infrared thermal images. Hong et al. [22] used a thermometer in order to record the rectal temperature of mice following Panax Ginseng and Panax quinquefolius administration under different environmental temperature conditions. Their study aimed to evaluate the effects of different environmental temperature conditions and herbal medicine administration on the body temperature.

Bach et al. [23] compared the differences noted between conductive and infrared devices that were used for the measurement of the mean skin temperature during the resting state, the exercise in the presence heat, and the recovery state. The authors concluded that infrared thermal imaging was not suitable for the detection of the motion status, while thermistor use resulted in high accuracy during resting and motion states. The use of the thermometer was not convenient for real-time monitoring and recording. Consequently, this present study utilized the thermistor equipment that has the advantage of detecting the body temperature for 24 hours following medicinal drug administration. Compared with the previous experimental method, this second method moreover excludes animal anesthesia interference.
In the current study, the characteristics of the cold and hot properties of the Chinese herbs were examined using the concept of the traditional Chinese medicine, and the acupuncture point specific theory. The study aimed to compare the different effects of prepared aconite root, dried ginger rhizome, and Coptis on the body temperature changes and to explore the sensitive points of the body that can reflect the herbal cold and hot properties. Rectal and skin temperature changes of Dazhui (GV14), Zhiyang (GV9), Mingmen (GV4), Zhongwan (CV12), and Shenque (CV8) acupuncture points were recorded for 24 hours prior to and following medicinal herb administration by the thermistor dynamic device.

\section{Materials and Methods}

2.1. Chinese Medicinal Herbs. Prepared aconite root, dried ginger rhizome, and Coptis were purchased from Beijing Tong Ren Tang Pharmacy (Beijing, China).

2.2. Animals and Grouping. A total of 33 adult male rabbits weighing $2.5 \mathrm{~kg} \pm 0.5 \mathrm{~kg}$ were used in the present study. They were housed in a room that was maintained at a constant temperature of $23 \pm 1^{\circ} \mathrm{C}$, a constant humidity of $45 \mathrm{p} .100 \pm$ $5 \mathrm{p} .100$, and a $12 \mathrm{~h}: 12 \mathrm{~h}$ light/dark cycle with light onset at 08:00 am. Drinking water and laboratory rodent chow were provided ad libitum. All studies on unanesthetized rabbits were conducted in the facilities of Beijing University of Chinese Medicine and were approved by the Institutional Animal Care and Use Committee (BUCM-3-20150325021002).

A total of 33 rabbits were randomly divided into 6 groups, including prepared aconite root (PAR) group (dosage A group $(n=4)$, dosage $\mathrm{B}$ group $(n=5))$, dried ginger rhizome (DGR) group (dosage A group $(n=6)$, dosage B group $(n=6))$, and Coptis (C) group (dosage A group $(n=6)$, dosage B group $(n=6))$.

2.3. Preparation of Decoction. Initially the ingredients were placed in an earthenware pot and clean water was added until all the ingredients were covered. The ingredients were soaked for $60 \mathrm{~min}$. Subsequently, the solution was boiled and simmered and the decoction was conducted by pouring water to the remaining precipitates. The new solution was heated repeatedly as described previously. The two decoctions were mixed together and the final concentrations of the herbal medicinal extracts were $1 \mathrm{~g} \cdot \mathrm{ml}^{-1}$ and $2 \mathrm{~g} \cdot \mathrm{ml}^{-1}$.

2.4. Herbal Dosage and Administration. The clinical herbal dosage conversion between human and rabbit was estimated based on a previous study [24]: human herbal dosage $\left(\mathrm{g} \cdot \mathrm{kg}^{-1}\right)$ : rabbit herbal dosage $\left(\mathrm{g} \cdot \mathrm{kg}^{-1}\right)=3.08: 1$. Provided that a person $(60 \mathrm{~kg})$ receives $10 \mathrm{~g}$ of each herb, the equivalent dose for a rabbit will be $0.513 \mathrm{~g} \cdot \mathrm{kg}^{-1}$. However the dosage for the rabbits used in the present study was 10 -fold higher (dosage A, $5.13 \mathrm{~g} \cdot \mathrm{kg}^{-1}$ ) and 20-fold higher (dosage B, $10.26 \mathrm{~g} \cdot \mathrm{kg}^{-1}$ ).

The herbs were administered intragastrically to the rabbits. 


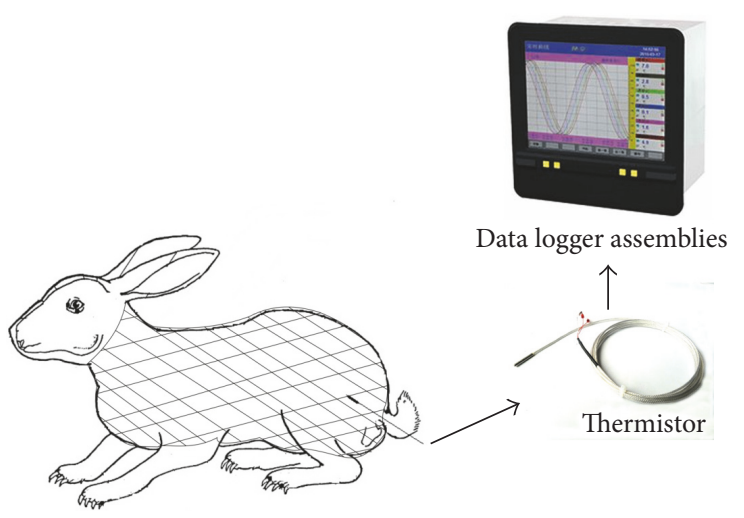

(a)

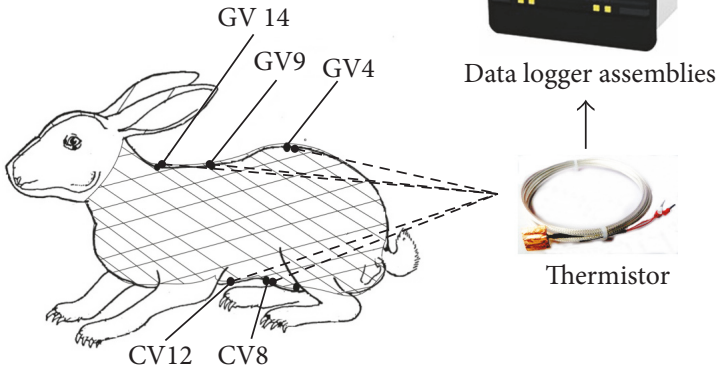

(b)

FIGURE 1: The procedure of temperature detection. (a) Rectal temperature detection. (b) Skin temperature detection.

\subsection{Apparatus}

Pt100 Thermistor. The temperature range used was between $-50^{\circ} \mathrm{C}$ and $200^{\circ} \mathrm{C}$. The accuracy was $\pm 0.2^{\circ} \mathrm{C}$. The appearance parameters of the chip type thermistor and cylindrical thermistor were $10 \mathrm{~mm} \times 10 \mathrm{~mm} \times 2 \mathrm{~m}$ and $3 \mathrm{~mm} \times 19 \mathrm{~mm} \times 2 \mathrm{~m}$ (diameter $\times$ length $\times$ line length) separately. The apparatuses were purchased from Shanghai Xinghua Xikai Equipment Co., Ltd (Shanghai, China).

Paperless Recorder. The screen used was 7 inch true color TFTLCD $(800 \times 480$ dot matrix $)$ and the accuracy was \pm 0.2 p.100 F.S. The recorder was purchased from Shanghai Xinghua Xikai Equipment Co., Ltd (Shanghai, China).

The temperature and humidity were set at a constant level of $26^{\circ} \mathrm{C} \pm 1^{\circ} \mathrm{C}$ and 55p.100 \pm 5p. 100 .

2.6. Acupuncture Points Location. The acupuncture points were located as follows.

Dazhui (GV14). The point was located in the posterior region of the neck, in the depression inferior to the spinous process of the seventh cervical vertebra (C7), on the posterior median line.

Zhiyang (GV9). The point was located in the upper back region, in the depression inferior to the spinous process of the seventh thoracic vertebra (T7), on the posterior median line.

Mingmen (GV4). The point was located in the lumbar region, in the depression inferior to the spinous process of the second lumbar vertebra (L2), on the posterior median line.

Zhongwan (CV12). The point was located on the upper abdomen, on the line between the xiphisternal junction and pubic symphysis (a total of 13 equal parts), 4 equal parts inferior to the xiphisternal junction.

Shenque (CV8). The point was located on the upper abdomen, on the line between the xiphisternal junction and pubic symphysis (a total of 13 equal parts), 5 equal parts superior to the pubic symphysis. The location of the acupuncture points was based on previous studies [25].

2.7. Procedure. The front and back fur of the rabbits was shaved by an electric hair clipper 24 hours prior to temperature detection. On the detection day, the acupuncture points were marked with a marker. Chip shaped thermistors were attached to the Dazhui (GV14), Zhiyang (GV9), Mingmen (GV4), Zhongwan (CV12), and Shenque (CV8) acupuncture points. A cylindrical thermistor was inserted into the rectum for $150 \mathrm{~mm}$. The perirectal area was covered with gauze in order to prevent loss of contact with the thermistor. The rabbits were wrapped with medical hollow elastic bandage. Following administration of water, the rabbits were put into a cage. The body temperature of the rabbits was recorded for $24 \mathrm{~h}$ at a constant temperature and humidity environment (with temperature $26^{\circ} \mathrm{C} \pm 1^{\circ} \mathrm{C}$, humidity $60 \mathrm{p} .100 \pm 5 \mathrm{p} .100$ ). On the third day following medicinal herb administration, the skin temperature of the acupuncture points and the rectal temperature were recorded for $24 \mathrm{~h}$. See Figure 1.

2.8. Statistical Analysis. Microsoft Excel 2010 software was used to calculate the temperature difference of the acupuncture points and rectum between medicinal herb administration and water administration. The temperature difference was defined as follows: $\Delta T, \Delta T=T_{\text {herbs }}-T_{\text {water }}$. A temperature difference of higher than $0^{\circ} \mathrm{C}\left(\Delta T>0^{\circ} \mathrm{C}\right)$ indicated that body temperature following herbal administration was superior to that following water administration, while a temperature difference of lower than $0^{\circ} \mathrm{C}\left(\Delta T<0^{\circ} \mathrm{C}\right)$ indicated that the body temperature following herbal administration was inferior to that following water administration. The mean temperature changes of the detected sites in each group were analyzed.

\section{Results}

3.1. The Effects of PAR, DRG, and C Dosage Groups on the Rectal Temperature Changes. The rectal temperature rose in 


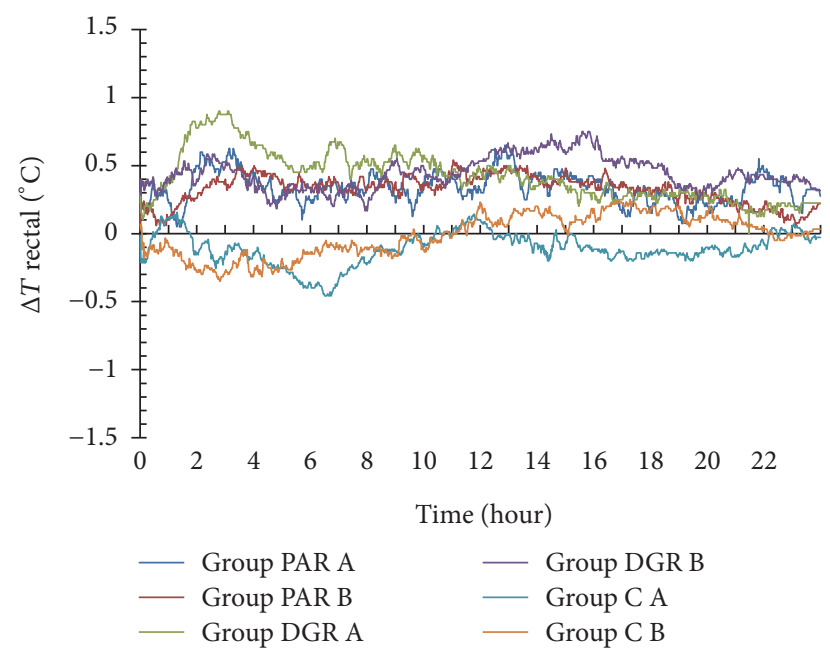

FIGURE 2: Rectal temperature changes within $24 \mathrm{~h}$ following herbal administration of PAR, DRG, and C (A and B) dosage groups.

both PAR A and PAR B dosage groups within $24 \mathrm{~h}$ of herbal administration (with $\Delta T>0^{\circ} \mathrm{C}$ ). The maximum rise in the temperature of the PAR A dosage group was $0.65^{\circ} \mathrm{C}$ following $13 \mathrm{~h}$ of herbal administration, while the maximum rise in the temperature of PAR B dosage group was $0.54^{\circ} \mathrm{C}$ following $11 \mathrm{~h}$ of herbal administration.

The rectal temperature rose in both DGR A and DGR $\mathrm{B}$ dosage groups within $24 \mathrm{~h}$ of herbal administration (with $\Delta T>0^{\circ} \mathrm{C}$ ). The maximum temperature of the DGR A dosage group was $0.9^{\circ} \mathrm{C}$ following $3.1 \mathrm{~h}$ of herbal administration, while the maximum temperature of the DGR B dosage group was $0.75^{\circ} \mathrm{C}$ following $16 \mathrm{~h}$ of herbal administration.

The rectal temperature dropped in the $\mathrm{C}$ A dosage group within $24 \mathrm{~h}$ following herbal administration (with $\Delta T<0^{\circ} \mathrm{C}$ ). The minimum temperature was $-0.46^{\circ} \mathrm{C}$ following $6.75 \mathrm{~h}$ of herbal administration. The rectal temperature dropped in the $\mathrm{C} B$ dosage group at $11.05 \mathrm{~h}$ following herbal administration (with $\Delta T<0^{\circ} \mathrm{C}$ ), whereas it was risen during the $11.1 \mathrm{~h}-22.17 \mathrm{~h}$ time interval (with $\Delta T>0^{\circ} \mathrm{C}$ ). The minimum temperature noted was $-0.35^{\circ} \mathrm{C}$ at $2.83 \mathrm{~h}$ following herbal administration. See Figure 2.

3.2. The Effects of PAR, DRG, and C Dosage Groups on the Skin Temperature Changes of the Acupuncture Point Dazhui (GV14). The skin temperature of the acupuncture point Dazhui (GV14) in the PAR A and PAR B dosage groups rose within $24 \mathrm{~h}$ following herbal administration (with $\Delta T>$ $0^{\circ} \mathrm{C}$ ), whereas the maximum temperature changes were $1.7^{\circ} \mathrm{C}$ at $12.67 \mathrm{~h}$ following herbal administration. The skin temperature of the Dazhui (GV14) acupuncture point in the PAR B dosage group dropped within $3.3 \mathrm{~h}$ following herbal administration (with $\Delta T<0^{\circ} \mathrm{C}$ ) and rose during the $3.3 \mathrm{~h}-24 \mathrm{~h}$ time interval (with $\Delta T>0^{\circ} \mathrm{C}$ ). The maximum temperature change was $0.88^{\circ} \mathrm{C}$ at the $13.62 \mathrm{~h}$ time period following herbal administration.

The skin temperature of the Dazhui (GV14) acupuncture point in DGR A and B dosage groups DGR rose within

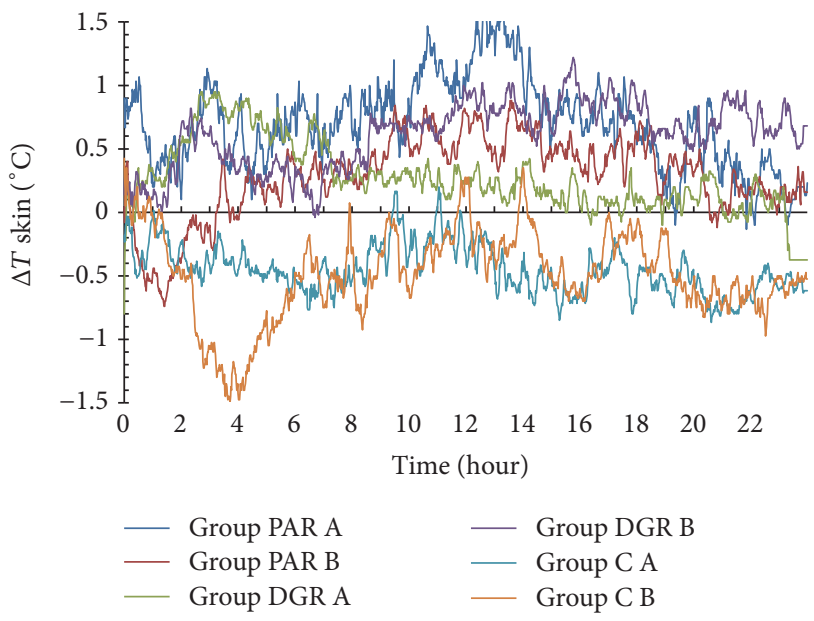

FIGURE 3: Skin temperature changes of the Dazhui (GV14) acupuncture point within $24 \mathrm{~h}$ of herbal administration of PAR, DRG, and C (A and B) dosage groups.

$24 \mathrm{~h}$ following herbal administration (with $\Delta T>0^{\circ} \mathrm{C}$ ), whereas the maximum temperature changes were $0.95^{\circ} \mathrm{C}$ at the time point of $3.22 \mathrm{~h}$ and $1.22^{\circ} \mathrm{C}$ at the time point of $15.75 \mathrm{~h}$, following herbal administration.

The skin temperature of the acupuncture point Dazhui (GV14) in C A and B dosage groups dropped within $24 \mathrm{~h}$ of herbal administration (with $\Delta T<0^{\circ} \mathrm{C}$ ), whereas the minimum temperature changes were $-0.77^{\circ} \mathrm{C}$ at $6.5 \mathrm{~h}$ and $-1.5^{\circ} \mathrm{C}$ at $3.73 \mathrm{~h}$, following herbal administration. See Figure 3.

3.3. The Effects of PAR, DRG, and C Dosage Groups on the Skin Temperature Changes of the Acupuncture Point Zhiyang (GV9). The skin temperature changes of the Zhiyang (GV9) acupuncture point in the PAR A dosage group rose during the $9 \mathrm{~h}-24 \mathrm{~h}$ interval periods (with $\Delta T>0^{\circ} \mathrm{C}$ ), whereas the maximum value was $1.15^{\circ} \mathrm{C}$ at $12.72 \mathrm{~h}$ following herbal administration. The skin temperature changes of the Zhiyang (GV9) acupuncture point in the PAR B dosage group dropped within $3.3 \mathrm{~h}$ following herbal administration (with $\Delta T<0^{\circ} \mathrm{C}$ ) and rose at the $3.3 \mathrm{~h}-24 \mathrm{~h}$ time interval (with $\Delta T>0^{\circ} \mathrm{C}$ ). The maximum value was $0.72^{\circ} \mathrm{C}$ at $13.58 \mathrm{~h}$ following herbal administration.

The skin temperature of the acupuncture point Zhiyang (GV9) in the DGR A and B dosage groups rose within $24 \mathrm{~h}$ following herbal administration (with $\Delta T>0^{\circ} \mathrm{C}$ ) and the maximum temperature changes were $1.28^{\circ} \mathrm{C}$ at $3.32 \mathrm{~h}$ and $1.1^{\circ} \mathrm{C}$ at $15.58 \mathrm{~h}$ following herbal administration.

The skin temperature changes of the acupuncture point Zhiyang (GV9) in the $\mathrm{C}$ A dosage group remained at $0^{\circ} \mathrm{C}$ with minor fluctuations and the minimum temperature value was $-0.29^{\circ} \mathrm{C}$ at $2.67 \mathrm{~h}$ following herbal administration. The skin temperature changes of the acupuncture point Zhiyang (GV9) in the C B dosage group dropped within $24 \mathrm{~h}$ following herbal administration with the exception of the $11.15 \mathrm{~h}-12.73 \mathrm{~h}$ time interval (with $\Delta T<0^{\circ} \mathrm{C}$ ). The minimum temperature change was $-0.83^{\circ} \mathrm{C}$ at $2.67 \mathrm{~h}$ following herbal administration. See Figure 4. 


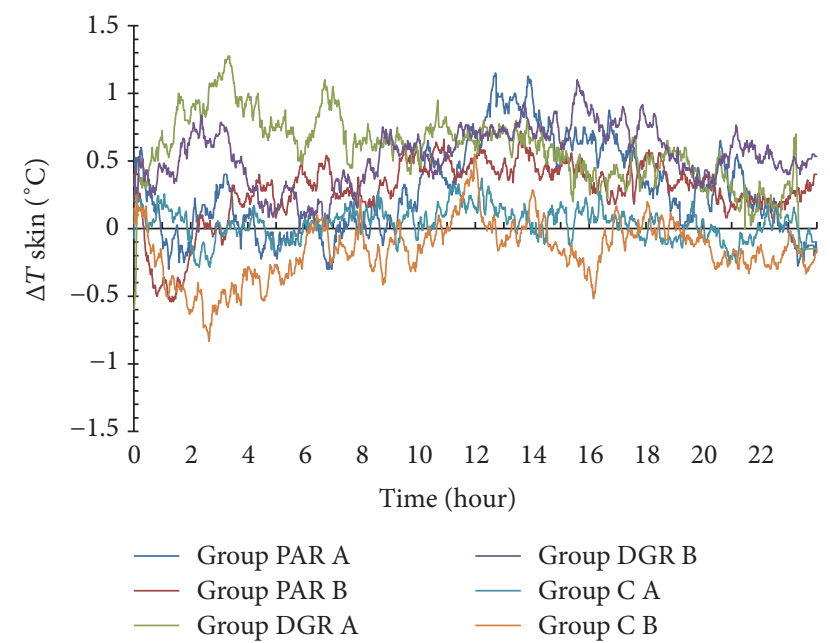

FIgURE 4: Skin temperature changes of the Zhiyang (GV9) acupuncture point within $24 \mathrm{~h}$ following herbal administration of the PAR, $\mathrm{DRG}$, and $\mathrm{C}$ ( $\mathrm{A}$ and $\mathrm{B})$ dosage groups.

3.4. The Effects of PAR, DRG, and C Dosage Groups on the Skin Temperature Changes of the Acupuncture Point Mingmen (GV4). The skin temperature changes of Mingmen (GV4) in the PAR A dosage group rose at the $9 \mathrm{~h}-24 \mathrm{~h}$ time intervals (with $\Delta T>0^{\circ} \mathrm{C}$ ) and the maximum temperature value was $1.03^{\circ} \mathrm{C}$ at $13.83 \mathrm{~h}$ following herbal administration. The skin temperature changes of Mingmen (GV4) in the PAR B dosage group dropped within $3.3 \mathrm{~h}$ following herbal administration (with $\Delta T<0^{\circ} \mathrm{C}$ ) and rose at the $3.3 \mathrm{~h}-24 \mathrm{~h}$ time interval (with $\Delta T>0^{\circ} \mathrm{C}$ ). The maximum temperature value was $0.46^{\circ} \mathrm{C}$ at the $13.67 \mathrm{~h}$ following herbal administration.

The skin temperature changes of the Mingmen (GV4) acupuncture point in the DGR A dosage group rose within $14.27 \mathrm{~h}$ following herbal administration (with $\Delta T>0^{\circ} \mathrm{C}$ ) and dropped at the $14.28 \mathrm{~h}-24 \mathrm{~h}$ time interval (with $\Delta T<0^{\circ} \mathrm{C}$ ). The maximum temperature value was $0.9^{\circ} \mathrm{C}$ at $6.67 \mathrm{~h}$ following herbal administration. The skin temperature changes of the Mingmen (GV4) acupuncture point in the DGR B dosage group rose within $24 \mathrm{~h}$ following herbal administration (with $\Delta T>0^{\circ} \mathrm{C}$ ). The maximum value was $0.75^{\circ} \mathrm{C}$ at $15.67 \mathrm{~h}$ following herbal administration.

The skin temperature of the Mingmen (GV4) acupuncture point in the $\mathrm{C} \mathrm{A}$ dosage group dropped at the $2.08 \mathrm{~h}-9.45 \mathrm{~h}$ time interval (with $\Delta T<0^{\circ} \mathrm{C}$ ) and rose at the $9.47 \mathrm{~h}-17.27 \mathrm{~h}$ time interval (with $\Delta T>0^{\circ} \mathrm{C}$ ) following herbal administration. The minimum value was $-0.28^{\circ} \mathrm{C}$ at $5.83 \mathrm{~h}$ following herbal administration. The skin temperature of the Mingmen (GV4) acupuncture point in the C B dosage group dropped within $9.08 \mathrm{~h}$ (with $\Delta T<0^{\circ} \mathrm{C}$ ), and remained at approximately $0^{\circ} \mathrm{C}$ during the $9.1 \mathrm{~h}-24 \mathrm{~h}$ time interval. The minimum temperature value was $-0.67^{\circ} \mathrm{C}$ at $2.5 \mathrm{~h}$ following herbal administration. See Figure 5.

3.5. The Effects of PAR, DRG, and C Dosage Groups on the Skin Temperature Changes of the Acupuncture Point Zhongwan (CV12). The skin temperature changes of the Zhongwan (CV12) acupuncture point in PAR A and B dosage groups rose

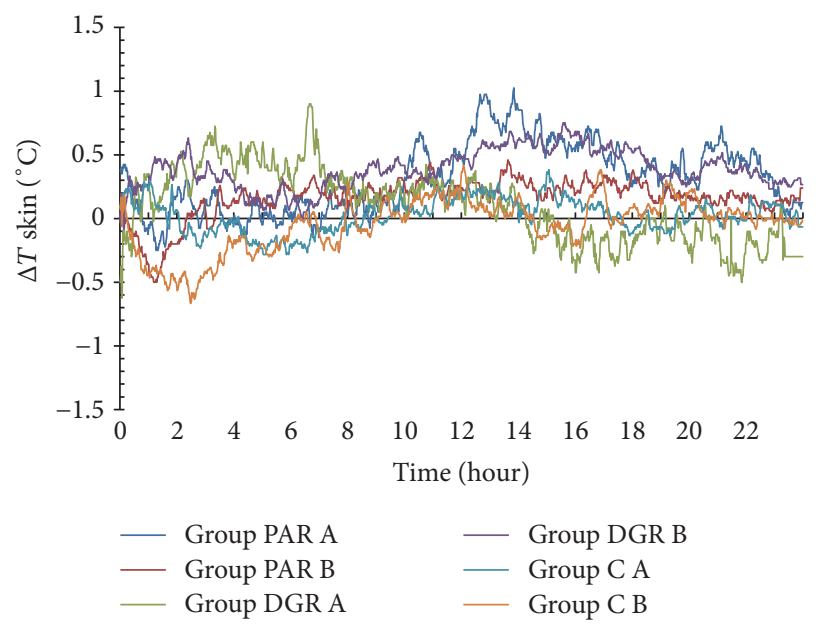

FIgURE 5: Skin temperature changes of the Mingmen (GV4) acupuncture point within $24 \mathrm{~h}$ of herbal administration of the PAR, DRG, and C (A and B) dosage groups.

within $24 \mathrm{~h}$ following herbal administration (with $\Delta T>0^{\circ} \mathrm{C}$ ). The maximum temperature values of the PAR $\mathrm{A}$ and $\mathrm{B}$ groups were $1.73^{\circ} \mathrm{C}$ at $14.25 \mathrm{~h}$ and $0.98^{\circ} \mathrm{C}$ at $9 \mathrm{~h}$, following herbal administration.

The skin temperature changes of the Zhongwan (CV12) acupuncture point in the DGR A and $\mathrm{B}$ dosage groups rose within $24 \mathrm{~h}$ following herbal administration (with $\Delta T>0^{\circ} \mathrm{C}$ ). The maximum temperature values were $1.23^{\circ} \mathrm{C}$ at $4.75 \mathrm{~h}$ and $0.98^{\circ} \mathrm{C}$ at $15.83 \mathrm{~h}$, following herbal administration.

The skin temperature change of the Zhongwan (CV12) acupuncture point in the $\mathrm{C} \mathrm{A}$ dosage group was approximately $0^{\circ} \mathrm{C}$ within $4.65 \mathrm{~h}$ following herbal administration and it dropped during the $4.67 \mathrm{~h}-8.57 \mathrm{~h}$ interval and during the $12.75 \mathrm{~h}-24 \mathrm{~h}$ interval (with $\Delta T<0^{\circ} \mathrm{C}$ ). The aforementioned temperature change rose at the $9 \mathrm{~h}-12.73 \mathrm{~h}$ time interval (with $\Delta T>0^{\circ} \mathrm{C}$ ), whereas the minimum temperature value was $-0.36^{\circ} \mathrm{C}$ at $7 \mathrm{~h}$ following herbal administration. The skin temperature changes of the Zhongwan (CV12) acupuncture point in the $\mathrm{C} B$ dosage group dropped during the $0.72 \mathrm{~h}-1.83 \mathrm{~h}$ interval $\left(\Delta T<0^{\circ} \mathrm{C}\right)$ and rose during the $1.85 \mathrm{~h}-24 \mathrm{~h}$ interval (with $\Delta T>0^{\circ} \mathrm{C}$ ). See Figure 6.

3.6. The Effects of the PAR, DRG, and C Dosage Groups on the Skin Temperature Changes of the Acupuncture Point Shenque (CV8). The skin temperature of the Shenque (CV8) acupuncture point in the PAR A dosage group dropped within $1.95 \mathrm{~h}$ (with $\Delta T<0^{\circ} \mathrm{C}$ ) and rose during the $1.95 \mathrm{~h}-24 \mathrm{~h}$ interval (with $\Delta T>0^{\circ} \mathrm{C}$ ) following herbal administration. The maximum temperature value was $1.5^{\circ} \mathrm{C}$ at $14.25 \mathrm{~h}$. The skin temperature of the Shenque (CV8) acupuncture point in the PAR B dosage group dropped during the $0.32 \mathrm{~h}-1.83 \mathrm{~h}$ interval (with $\Delta T<0^{\circ} \mathrm{C}$ ) and rose during the $1.83 \mathrm{~h}-24 \mathrm{~h}$ interval (with $\Delta T<0^{\circ} \mathrm{C}$ ) following herbal administration. The maximum temperature value was $1.12^{\circ} \mathrm{C}$ at $9 \mathrm{~h}$ following herbal administration.

The skin temperature changes of the Shenque (CV8) acupuncture point in the DGR A and B dosage groups rose 


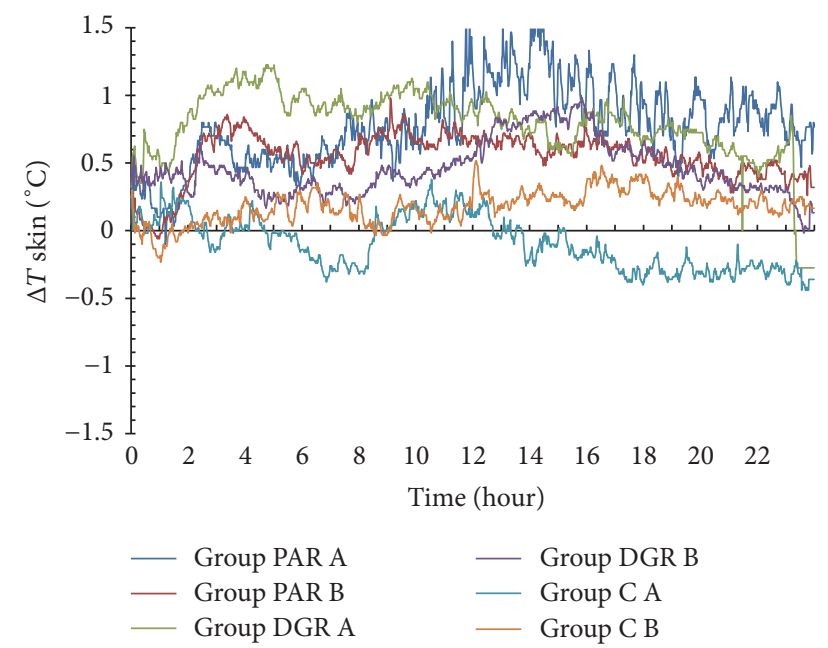

Figure 6: Skin temperature changes of the Zhongwan (CV12) acupuncture point within $24 \mathrm{~h}$ of herbal administration of the PAR, $\mathrm{DRG}$, and $\mathrm{C}$ (A and $\mathrm{B})$ dosage groups.

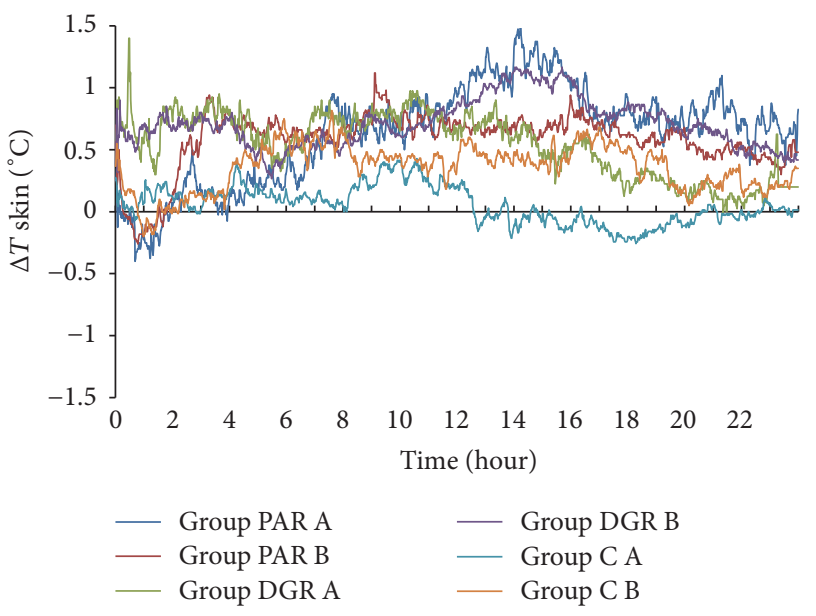

FIGURE 7: Skin temperature changes of the Shenque (CV8) acupuncture point within $24 \mathrm{~h}$ of herbal administration of the PAR, DRG, and $\mathrm{C}(\mathrm{A}$ and $\mathrm{B})$ dosage groups.

within $24 \mathrm{~h}$ of herbal administration (with $\Delta T>0^{\circ} \mathrm{C}$ ) and the maximum temperature values were $0.98^{\circ} \mathrm{C}$ at $10.37 \mathrm{~h}$ and $1.17^{\circ} \mathrm{C}$ at $14 \mathrm{~h}$.

The skin temperature changes of the Shenque (CV8) acupuncture point in the $\mathrm{C}$ A dosage group rose within $12.6 \mathrm{~h}$ of herbal administration (with $\Delta T>0^{\circ} \mathrm{C}$ ) and dropped at the $12.6 \mathrm{~h}-24 \mathrm{~h}$ time interval (with $\Delta T<0^{\circ} \mathrm{C}$ ). The minimum temperature value was $-0.26^{\circ} \mathrm{C}$ at $18.33 \mathrm{~h}$ following herbal administration. The skin temperature changes of the Shenque (CV8) acupuncture point in the C B dosage group dropped during the $0.72 \mathrm{~h}-1.83 \mathrm{~h}$ time interval (with $\Delta T<$ $0^{\circ} \mathrm{C}$ ) and rose during the $1.85 \mathrm{~h}-24 \mathrm{~h}$ interval (with $\Delta T>$ $0^{\circ} \mathrm{C}$ ). The minimum value was $-0.2^{\circ} \mathrm{C}$ following $1 \mathrm{~h}$ of herbal administration. See Figure 7.

\section{Discussions}

In the present study, the different effects of prepared aconite root, dried ginger rhizome, and Coptis were compared with regard to the body temperature changes, whereas the sensitive points of the body that can reflect their cold and hot properties were further explored. The rectal and skin temperature of the Dazhui (GV14), Zhiyang (GV9), Mingmen (GV4), Zhongwan (CV12), and Shenque (CV8) acupuncture points were detected by a thermistor dynamic device at $24 \mathrm{~h}$ prior to and following medicinal herb administration.

4.1. The Effects of Prepared Aconite Root (PAR) on the Rectal and Skin Temperature Changes of the Acupuncture Points. The results indicated that the rectal and skin temperature of the Dazhui (GV14), Zhiyang (GV9), Mingmen (GV4), Zhongwan (CV12), and Shenque (CV8) acupuncture points rose following herbal administration.

The thermal sensitive points on the surface of the body in the PAR A and B dosage groups manifested as Zhongwan (CV12) and Shenque (CV8) separately.

The heating intensities of each detection site in the PAR A dosage group were decreased in turn as follows: Zhongwan $\left(\mathrm{CV} 12, \Delta T_{\max }=1.73^{\circ} \mathrm{C}\right)$, Dazhui $(\mathrm{GV} 14)\left(\Delta T_{\max }=1.7^{\circ} \mathrm{C}\right)$, Shenque (CV8) $\left(\Delta T_{\max }=1.5^{\circ} \mathrm{C}\right)$, Zhiyang (GV9) $\left(\Delta T_{\max }=\right.$ $\left.1.15^{\circ} \mathrm{C}\right)$, and Mingmen $(\mathrm{GV} 4)\left(\Delta T_{\max }=1.03^{\circ} \mathrm{C}\right)$. The rectal temperature change was $\Delta T_{\max }=0.65^{\circ} \mathrm{C}$. The heating intensities of each detection site in the PAR B dosage group were decreased in turn as follows: Shenque (CV8, $\Delta T_{\max }=$ $\left.1.12^{\circ} \mathrm{C}\right)$, Zhongwan $\left(\mathrm{CV} 12, \Delta T_{\max }=0.98^{\circ} \mathrm{C}\right)$, Dazhui (GV14, $\left.\Delta T_{\max }=0.88^{\circ} \mathrm{C}\right)$, Zhiyang $\left(\mathrm{GV} 9, \Delta T_{\max }=0.72^{\circ} \mathrm{C}\right)$, and Mingmen $\left(\mathrm{GV} 4, \Delta T_{\max }=0.46^{\circ} \mathrm{C}\right)$. The rectal temperature change was $\Delta T_{\max }=0.54^{\circ} \mathrm{C}$.

4.2. The Effects of Dried Ginger Rhizome (DGR) on the Rectal and Skin Temperature Changes of the Acupuncture Points. The results indicated that the rectal and skin temperature of the Dazhui (GV14), Zhiyang (GV9), Mingmen (GV4), Zhongwan (CV12), and Shenque (CV8) acupuncture points rose following herbal administration. The thermal sensitive points on the surface of the body in the DGR A and B dosage groups manifested as the Zhiyang (GV9) and Dazhui (GV14) acupuncture points.

The heating intensities of each detection site in the DGR A dosage group were decreased in turn as follows: Zhiyang (GV9, $\left.\Delta T_{\max }=1.28^{\circ} \mathrm{C}\right)$, Zhongwan $\left(\mathrm{CV} 12, \Delta T_{\max }=\right.$ $\left.1.23^{\circ} \mathrm{C}\right)$, Shenque $\left(\mathrm{CV} 8, \Delta T_{\max }=0.98^{\circ} \mathrm{C}\right)$, Dazhui $(\mathrm{GV} 14$, $\left.\Delta T_{\max }=0.95^{\circ} \mathrm{C}\right)$, and Mingmen $\left(\mathrm{GV} 4, \Delta T_{\max }=0.9^{\circ} \mathrm{C}\right)$. The rectal temperature change was $\Delta T_{\max }=0.9^{\circ} \mathrm{C}$. The heating intensities of each detection site in the FGR $B$ dosage group were decreased in turn as follows: Dazhui (GV14, $\Delta T_{\max }=$ $1.22^{\circ} \mathrm{C}$ ), Shenque $\left(\mathrm{CV} 8, \Delta T_{\max }=1.17^{\circ} \mathrm{C}\right)$, Zhiyang (GV9, $\left.\Delta T_{\max }=1.1^{\circ} \mathrm{C}\right)$, Zhongwan $\left(\mathrm{CV} 12, \Delta T_{\max }=0.98^{\circ} \mathrm{C}\right)$, and Mingmen $\left(\mathrm{GV} 4, \Delta T_{\max }=0.75^{\circ} \mathrm{C}\right)$. The rectal temperature change was $\Delta T_{\max }=0.75^{\circ} \mathrm{C}$.

4.3. The Effect of Coptis (C) on the Rectal and Skin Temperature Changes of the Acupuncture Points. The results indicated that the rectal and skin temperature of the Dazhui (GV14) and 
Zhongwan (CV12) acupuncture points dropped following herbal administration, while the skin temperature changes of the Mingmen (GV4) acupuncture point manifested by a drop and a subsequent rise. The skin temperature changes of the Shenque (CV8) acupuncture point manifested by an initial rise and a subsequent drop. No prominent temperature changes were noted with regard to the Zhiyang (GV9) acupuncture point. The rectal and skin temperature changes of the Mingmen (GV4) acupuncture point in the C B dosage group were detected by an initial drop and a subsequent rise, whereas the skin temperature changes of the Dazhui (GV14) and Zhiyang (GV9) acupuncture points were detected by a drop and the skin temperature changes of the Zhongwan (CV12) and Shenque (CV8) acupuncture points by a rise. The temperature of the acupuncture points varied according to the dose of the medicinal herb. The thermal effects in the $\mathrm{C}$ $\mathrm{A}$ and $\mathrm{B}$ dosage groups exhibited concomitant rise and drop in the temperature. The thermal sensitive point was defined as the Dazhui (GV14) acupuncture point in group C.

The cooling intensities of each detection site in the $\mathrm{C}$ A dosage group were decreased in turn as follows: Dazhui $\left(\mathrm{GV14}, \Delta T_{\min }=-0.77^{\circ} \mathrm{C}\right)$, rectal temperature $\left(\Delta T_{\min }=\right.$ $\left.-0.46^{\circ} \mathrm{C}\right)$, Zhongwan $\left(\mathrm{CV} 12, \Delta T_{\min }=-0.36^{\circ} \mathrm{C}\right)$, Zhiyang $\left(\mathrm{GV} 9, \Delta T_{\min }=-0.29^{\circ} \mathrm{C}\right)$, Mingmen $\left(\mathrm{GV} 4, \Delta T_{\min }=\right.$ $\left.-0.28^{\circ} \mathrm{C}\right)$, and Shenque $\left(\mathrm{CV} 8, \Delta T_{\min }=-0.26^{\circ} \mathrm{C}\right)$.

The cooling intensities of each detection site in the $\mathrm{C}$ $\mathrm{B}$ dosage group were decreased in turn as follows: Dazhui $\left(\mathrm{GV} 14, \Delta T_{\min }=-1.5^{\circ} \mathrm{C}\right)$, Zhiyang $\left(\mathrm{GV} 9, \Delta T_{\min }=-0.83^{\circ} \mathrm{C}\right)$, Mingmen $\left(\mathrm{GV} 4, \Delta T_{\min }=-0.67^{\circ} \mathrm{C}\right)$, rectal temperature $\left(\Delta T_{\min }=-0.35^{\circ} \mathrm{C}\right)$, Zhongwan $\left(\mathrm{CV} 12, \Delta T_{\min }=-0.23^{\circ} \mathrm{C}\right)$, and Shenque $\left(\mathrm{CV} 8, \Delta T_{\min }=-0.2^{\circ} \mathrm{C}\right)$.

In summary, the effects of prepared aconite root and dried ginger rhizome on the temperature changes notably manifested as a warming up effect, and the thermal sensitive points on the body surface were the Zhongwan (CV12), Shenque (CV8), Dazhui (GV14), and Zhiyang (GV9) acupuncture points. The effect of Coptis on the temperature changes exhibits a simultaneous rise and drop, and the thermal sensitive point on the body surface was the Dazhui (GV14) acupuncture point. The present study indicated that the effects of Chinese herbs with cold and/or hot properties on the body temperature changes were noted on the Dazhui (GV14) acupuncture point.

In Chinese medicine, the use of prepared aconite root affects the meridians of the kidney, heart, and spleen organs and acts by recuperating the depleted yang and rescuing the patient from collapse. This effect supplements the "fire of the gate of life" and restores yang, expelling cold in order to relieve pain. Dried ginger rhizome affects the meridians of spleen, stomach, heart, and lung organs, which exert the functions of warming at the middle energizer meridian and dispelling cold. This results in recuperating the depleted yang and warming the lungs to resolve fluid retention. The Coptis herb affects the meridians of heart, liver, stomach, and large intestine organs and exerts functions of heat clearance and dampness elimination. In addition, it eliminates pathogenic fire and aids the detoxication [26]. In the traditional meridian and collateral theories, acupoints Zhongwan (CV12) and
Shenque (CV8) are located in the conception vessel. Zhongwan (CV12) is the Front-Mu point of the stomach and the influent point of all the fu organs, which acts by strengthening the spleen and the stomach and promoting digestive function, thus replenishing the Qi of the Middle energizer and tranquilizing the mind [27]. Recent studies indicated that Zhongwan (CV12) acupuncture point is associated with related acupuncture points in the conception vessel, governor vessel, and bladder meridian of the foot taiyang, such as acupoints Feishu (BL13), Xinshu (BL15), Ganshu (BL18), Pishu (BL20), Shenshu (BL23), and Dachangshu (BL25) [28]. Therefore, Zhongwan (CV12) is very effective for the treatment of the disorders associated with these related $z a n g$ $f u$ organs. Acupoint Shenque (CV8) exhibits the function of warming the middle energizer meridian in order to relieve diarrhea, recuperating yang, avoiding yang exhaustion and identifying specific channels in order to stop pain. It is closely associated with the 12 meridians and internal organs. The Shenque (CV8) acupuncture point is the stimulus for the regulation of the dysfunction of zang fu organs and meridians in addition to its function as a reaction point of physiological and pathological changes of viscera, meridian and collaterals, qi, and blood [29]. The Zhiyang (GV9) and Dazhui (GV14) acupuncture points are located on the governor vessel and are considered the yang vigorous points. The Zhiyang (GV9) acupuncture point has the function of exciting yang qi. It can reinforce qi and strengthen yang, nourish the blood, and quicken the collaterals by moxibustion. The functions of the latter aforementioned acupuncture point are notably the excitation of yang qi of the whole body, the warming and dissolution of the cold properties, the release of the channels, the quickening of the collaterals, and the redirection of the qi flow in order to loosen the center that is stimulated by acupuncture [30]. The Dazhui (GV14) acupuncture point is considered the connecting point of the governor vessel and the three yang meridians of the hand and foot, which are essential in the excitation of the yang qi. It is the commonly used heat clearing and yang qi reinforcing point in the clinic [31]. In the present study, the thermal sensitive points were reflected on the body surface by prepared aconite root, dried ginger rhizome, and Coptis in order to adjust their application to the description of the meridian tropism theory of the Chinese medicine. It states that the skin temperature changes prominently appear at the Zhongwan (CV12), Shenque (CV8), Dazhui (GV14), and Zhiyang (GV9) acupuncture points. It has been shown that the regulation of the internal organs by the drugs is closely related to the meridian tropism and clinical efficacy. The present study further confirms that the theory of traditional Chinese medicine is related to the theory of acupuncture points and internal organs, which provides evidence for the scientific use of this type of medicine in the clinic.

In TCM, meridian and collaterals have connective and communicative functions between internal organs and the body surface. The meridian and collaterals are considered the key components required for the circulation of the qi and blood, while the acupuncture points are notably the points on the surface of the body where the vital energy of the viscera is infused. The functional status of the viscera can be reflected by the corresponding acupuncture points 
and/or meridians on the surface of the body [3]. In the present study, the cold/hot properties and meridian tropism of the Chinese herbs were reflected by the corresponding acupuncture points. This confirmed an association between the meridian tropism of medicine and the acupuncture points that was in agreement with the hypothesis of the acupuncture points/meridians and zang fu organs.

A similar study focused on the application of an infrared thermal camera in order to detect the skin temperature of the lower abdomen, uterus area, governor vessel, and Shenque (CV8) acupuncture point so as to evaluate the drug targeting of the Left-Restoring Pill (zuo gui wan) and of the RightRestoring Pill (you gui wan). The results indicated that the drug targeting was focused on the governor vessel and the Shenque (CV8) acupuncture point, which demonstrated that the cold and hot properties caused by the drug treatment exerted a clear reaction site on the body [32]. The results of the aforementioned study were consistent with the results of the present study that further explored the specific response of a single herbal medicine on the governor and conception vessels and provided an experimental basis for the effects of different cold and hot herb-induced medical properties caused to the body.

One way to regulate the body temperature is through blood supply towards the skin. When the body temperature decreased, the blood vessel will constrict and a mass of heat will be taken from the skin, leading to the decreased skin temperature. In the same way, when the body temperature increased, blood will flow to the skin surface, leading to a rise of skin temperature. In a stable environment, the average body temperature can predict the body's thermal response [33]. In this study, the effects of prepared aconite root and dried ginger rhizome on the rectal and skin temperature changes were mainly manifested as warming effects, while the effects of Coptis on the rectal and skin temperature changes were mainly manifested as cooling effects. This may be related to the hot property of prepared aconite root and dried ginger rhizome, which can dilate blood vessels and lead to rise of the skin temperature. In contrast, the cold property of Coptis may induce vasoconstriction and skin temperature drop.

\section{Conclusion}

In this study, thermistor dynamic device was applied to explore the effect of cold/hot-natured Chinese herbs on the skin surface of corresponding acupoints, which preliminarily proved the objective existence of specific points reflecting the cold/hot property of Chinese herbs, and the dynamic thermoregulation changes were partly observed after herbal administration. The thermoregulation of cold/hot-natured Chinese herbs can be reflected on different acupoints. Furthermore, cold/hot-natured Chinese herbs have their own specific sensitive surface points. Both cold and hot-natured Chinese medicine can cause changes of the body temperature including rise and drop.

This study accumulated rich experience in the methodology exploration of cold and hot property in TCM. However, there are still some limitations and one-sidedness. For instance, the cold and hot property of some herbs cannot be fully reflected through relevant acupoints on the conception and governor vessels, which illustrated the complexity of Chinese herbal properties and their multisystem regulation on the body. This study provides experimental evidence for methodology exploration of Chinese herbs' four properties, and more sites will be chosen in our further study, including acupoints, ears, and internal organs.

\section{Conflicts of Interest}

The authors declare no conflicts of interest.

\section{Acknowledgments}

This work was partially supported by the NSF of China (Grant no. 11374016), the National Science and Technology funding body (Grant no. 2016YFA0200800), and the Young Talents Program under Beijing Municipal Education Commission (Grant no. YETP0789).

\section{References}

[1] G. W. Liu, Chinese Herbal Medicines, Hua Xia publishing house, Beijing, China, 1st edition, 2001.

[2] S. M. Liang, "Discussion of the four properties and five flavors of Chinese herbal medicine," New Journal of Traditional Chinese Medicine, vol. no.1, pp. 55-56, 1982.

[3] J.-M. Yang, X.-Y. Shen, L. Zhang et al., "The effect of acupuncture to sp6 on skin temperature changes of SP6 and SP10: An observation of "deqi"," Evidence-Based Complementary and Alternative Medicine, vol. 2014, Article ID 595963, 7 pages, 2014.

[4] G. W. Liu, Fundamentals of Formulas of Chinese Medicine, Hua Xia Publishing House, Beijing, China, 1st edition, 2002.

[5] X. B. Jiang and N. N. Jiang, "The cold and hot quantification of Chinese herbs and the principle of the minimum amount of cold and hot quantification," Journal of Traditional Chinese Medicine, vol. 44, no. 7, pp. 548-550, 2003.

[6] R. Jin, B. Zhang, X. Liu et al., "A theoretical and experimental study on the fuzzy evaluation model of biological performance of Chinese materia medica with an either cold or hot herbal property," Journal of Chinese Integrative Medicine, vol. 10, no. 10, pp. 1106-1119, 2012.

[7] H. W. Wang and Y. L. Dou, "Hypotheses of macroscopic drug nature and numerical simulation of component drug nature of traditional," World Science and Technology/Modernization of Traditional Chinese Medicine and Materia Medica, vol. 14, no. 2, pp. 1529-1531, 2012.

[8] Y. Sun, F. J. Zheng, Y. S. Gao, P. N. Zhao, D. N. Wang, and Y. H. $\mathrm{Li}$, "The research of formula quantification based on the fourproperty theory of Chinese medicine," World Chinese Medicine, vol. 10, no. 1, pp. 17-21, 2015.

[9] C. P. Zhou, J. B. Wang, X. R. Zhang et al., "Investigation of the differences between the "COLD" and "HOT" nature of Coptis chinensis Franch and its processed materials based on animal's temperature tropism," SCIENCE CHINA Life Sciences, vol. 52, no. 11, pp. 1073-1080, 2009.

[10] Z.-Y. Sun, Y.-L. Zhao, J.-B. Wang et al., "Research on Fuzi based on animal thermotropism behavior to discover if it has fewer "hot" characteristics without Ganjiang," Journal of Traditional Chinese Medicine, vol. 32, no. 2, pp. 208-214, 2012. 
[11] M. Zhu, Y. H. Li, T. X. Lin, Z. R. Yue, D. M Jing, and F. Ge, "Application of TTM system for testing Chinese herbal nature," Chinese Journal of Stereology and Mage Rectalysis, vol. 12, no. 1, pp. 53-58, 2007.

[12] Y. S. Gao, F. J. Zheng, X. Li, H. Xu, S. J. Z hang, and Y. H. Li, "A Microcalorimetric Research on the effect of traditional Chinese medicine on the growth and metabolism of E. coli," Journal of Yunnan University of Traditional Chinese Medicine, vol. 37, no. 2, pp. 10-13, 2014.

[13] W.-W. Cheng, J.-L. Liu, N. Zhang, H.-M. Li, C.-L. Wang, and J.-F. Jia, "Experimental method for evaluating cold and hot characteristic of traditional Chinese medicine," Chinese Traditional and Herbal Drugs, vol. 41, no. 7, pp. 1122-1126, 2010.

[14] Z. Wang, N. Zhang, Y. N. Sun, and J. L. Liu, "Evaluation of cold-heat characteristics of Pulsatillae Radix," Drug Evaluation Research, vol. 36, no. 5, pp. 359-362, 2013.

[15] J. Fu, J. Pang, X. Zhao, and J. Han, "The Quantitative Ideas and Methods in Assessment of Four Properties of Chinese Medicinal Herbs," Cell Biochemistry and Biophysics, vol. 71, no. 3, pp. 1307-1312, 2015.

[16] J. Han, M. Yang, and Y. Chen, "Quantum: may be a new-found messenger in biological systems," Bioscience Trends, vol. 5, no. 3, pp. 89-92, 2011.

[17] Q. C. Ma, Effects of Mankshood, Dry ginger, Chinese goldthread, Rhubarb on signs of cold and heat and on energy metabolism in rats, Shandong University of Chinese Medicine, Shandong, China, 2007.

[18] R. Zhou, X. F. Meng, and Y. Hui, "Research on four nature drugs about fat metabolism in rats," Asia-Pacific Traditional Medicine, vol. 6, no. 1, pp. 39-41, 2010.

[19] K. Sałat and B. Filipek, "Antinociceptive activity of transient receptor potential channel TRPV1, TRPA1, and TRPM8 antagonists in neurogenic and neuropathic pain models in mice," Journal of Zhejiang University SCIENCE B, vol. 16, no. 3, pp. 167178, 2015.

[20] J.-F. Jiang, Y.-G. Wang, J. Hu et al., "Novel effect of berberine on thermoregulation in mice model induced by hot and cold environmental stimulation," PLoS ONE, vol. 8, no. 1, Article ID e54234, 2013.

[21] Y. M. Yuan, X. Chen, Z. Q. Pan, K. Cheng, Y. Gong, and M. J. Liao, "Study on infrared thermal imaging of rat model with cold and hot syndromes," Liaoning Journal of Traditional Chinese Medicine, vol. 35, no. 5, pp. 785-787, 2008 (Chinese).

[22] B. N. Hong, M. H. Do, Y. R. Her, Y. R. Lee, and T. H. Kang, "The effects of panax ginseng and panax quinquefolius on thermoregulation in animal models," Evidence-Based Complementary and Alternative Medicine, vol. 2015, Article ID 748041, 8 pages, 2015.

[23] A. J. E. Bach, I. B. Stewart, A. E. Disher, and J. T. Costello, "A comparison between conductive and infrared devices for measuring mean skin temperature at rest, during exercise in the heat, and recovery," PLoS ONE, vol. 10, no. 2, Article ID e0117907, 2015.

[24] H. J. Huang, H. X. Huang, and Y. Z. Chen, "Dose conversion among different animals and healthy volunteers in pharmacological study," Chinese Journal of Clinical Pharmacology and Therapeutics, vol. 9, no. 9, pp. 1069-1072, 2004.

[25] L. F. Zhang, Experimental acupuncture science, Chemical industry press, Beijing, China, 2010, edition.

[26] X. M. Gao, Chinese Herbal Medicinal, Peoples Medical Publishing House, Beijing, China, 2nd edition, 2013.
[27] T. W. Zuo, "Clinical research progress of Zhongwan in recent years," Harbin Medical Journal, vol. 31, no. 6, pp. 456-457, 2011.

[28] C. J. Wei, "Exploration of the meridian and collateral distribution of Zhongwan," Traditional Chinese Clinical and Healthcare Medicine, vol. 1, no. 1, pp. 29-30, 1989.

[29] X. G. Wu, "Textual research on acupuncture and moxibustion of Shenque," Chinese Society of Acupuncture andMoxibustion, pp. 12-15, 2011.

[30] L. L. Zhao, Y. Y. Wang, C. P. Zhang, and R. Wang, "Clinical treatment of Zhi Yang points," Jilin Journal of Traditional Chinese Medicine, vol. 36, no. 6, pp. 623-625, 2016.

[31] W. Z. Cao, A. M. Li, R. W. Dai, and Z. G. Zhang, "A study and explanation on acupoint Dazhui (GV14)," Journal of Sichuan of Traditional Chinese Medicine, vol. 30, no. 12, pp. 32-34, 2012.

[32] X. Zheng, Y.-L. Deng, Q.-J. Li, and H. Lu, "Assessing drug targeting of Yougui Pill, Zuogui Pill, and their disassembled prescriptions using infrared thermography," Zhongguo Zhongxiyi Jiehe Zazhi, vol. 34, no. 4, pp. 446-449, 2014.

[33] X. Du, B. Li, H. Liu et al., "The response of human thermal sensation and its prediction to temperature step-change (coolneutral-cool)," PLoS ONE, vol. 9, no. 8, Article ID e104320, 2014. 


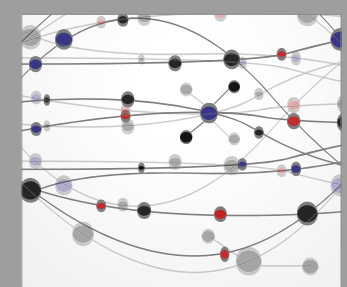

The Scientific World Journal
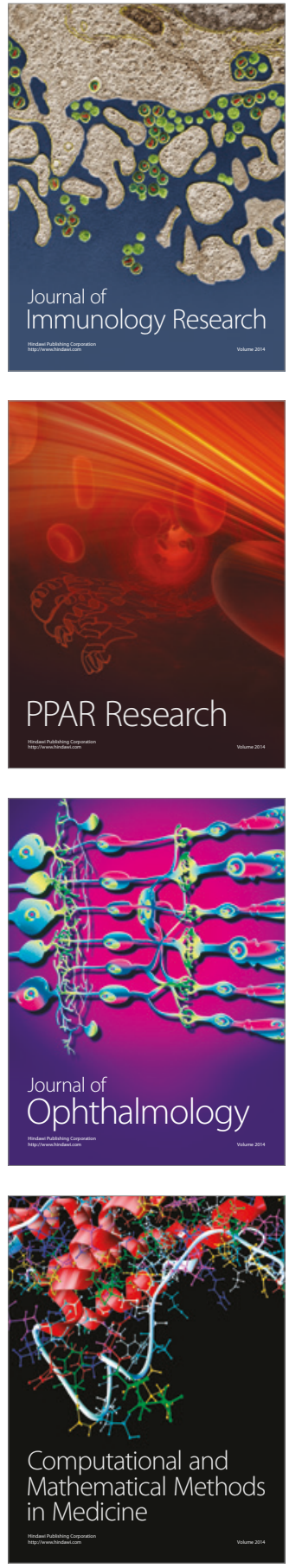

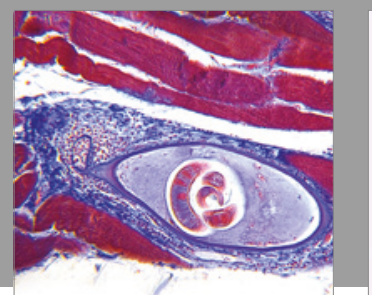

Gastroenterology Research and Practice
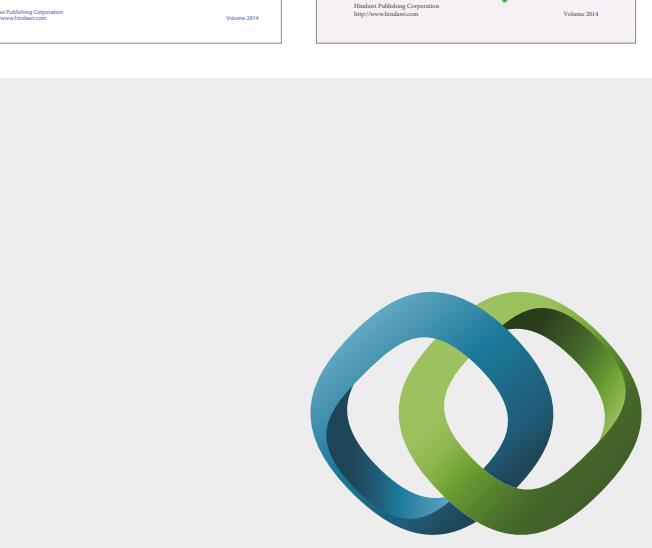

\section{Hindawi}

Submit your manuscripts at

https://www.hindawi.com
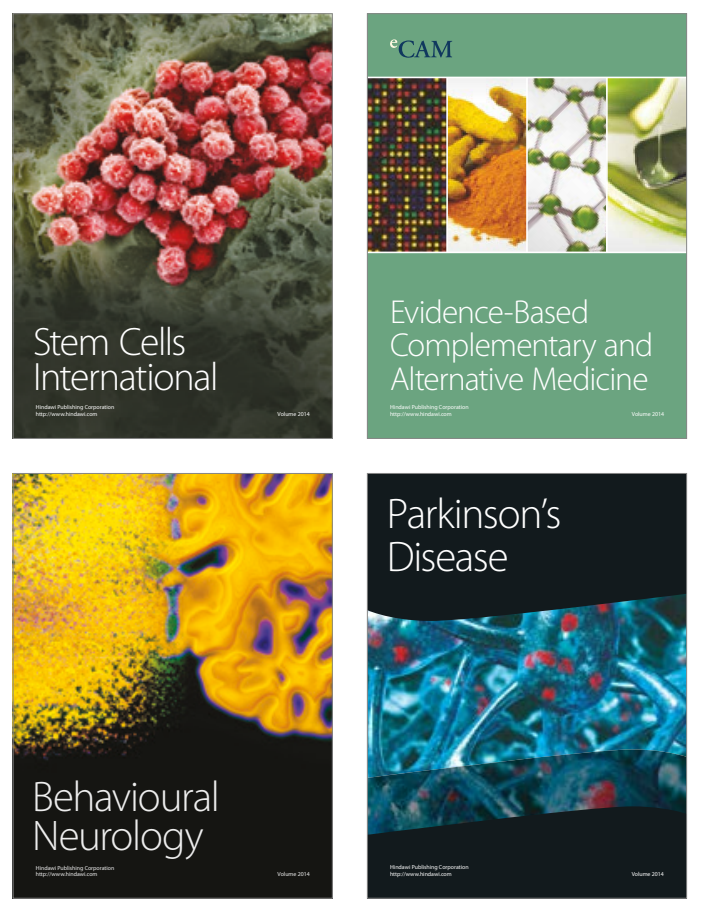
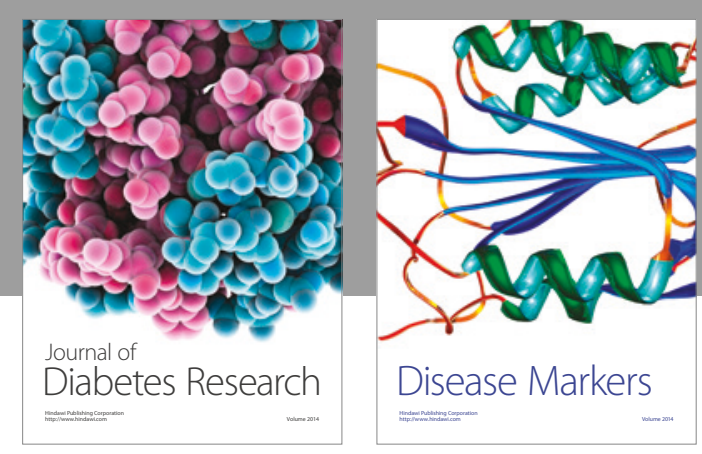

Disease Markers
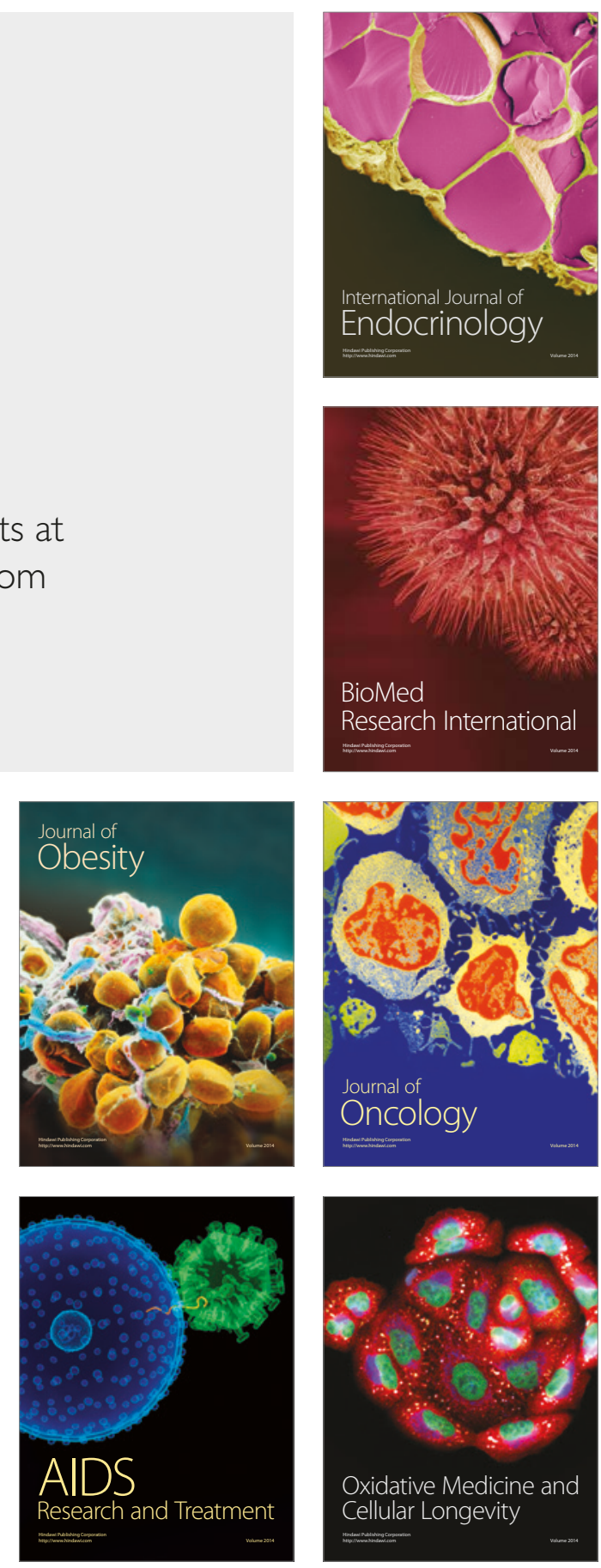